\title{
Repairing Individual Trust in Organizational Setting: The Mediating and Moderating Role of Benevolence and Competence Based
}

\author{
Helen Agbornso Ashu ${ }^{1 *}$ Olayemi Hafeez Rufai ${ }^{2} \quad$ Angwi Tassang ${ }^{3} \quad$ Annabelle Gadabu $^{1}$ \\ Basiru Ibrahim ${ }^{1} \quad$ Adebayo Olufemi David ${ }^{4}$ Victoria Omoladun Oludu ${ }^{5}$ Richard Oluwole Alademomi ${ }^{1}$ \\ 1.School of Public Affairs, University of Science and Technology of China, Hefei Anhui, 230026, PR China \\ 2.School of Social Sciences and Humanities, Department of Culture and Media Communication, University of \\ Science and Technology of China, Hefei Anhui, 230026, PR China \\ 3.School of Public Administration, Department of Sociology, Hohai University, Nanjing, PR China \\ 4.College of Teacher Education, Department of Comparative Education, Zhejiang Normal University, Zhejiang, \\ PR China \\ 5.School of Management, Department of Business Administration, Hefei University of Technology Anhui, \\ 230026, PR China
}

\begin{abstract}
Introduction: Trust is a social construct that is present in the day-to-day routine of humans negative events such as product failure, revelations of corrupt practices, and unfulfilled promises could distort trusting relationships, develop negative future expectations, and in due course lead to trust violations. To maintain or restore the resultant loss of trust, organizations must examine and understand how trust was violated in the first place since different means of damaged trust are likely to require different reparative responses.

Objectives: This study investigates how individual trust is repaired in an organization using apology and justification as means of repairing competence -based and benevolence-based trust violations.

Study Design: Using a medical practitioner working in a private medical foundation called Save the Child Foundation, this research adopts a quantitative survey methodology using self-administered questionnaires to collect data from 304 patients and workers from a fictitious medical hospital in Cameroon. Hypothesis testing was carried out using structural equation modeling and regression analyses.

Results: Through a scenario questionnaire survey, the study provided support for all of the hypotheses. Hypotheses 1 and 3 focused on the strategies of repairing trust. The result shows that benevolence had a mediating effect on apology, justification and trust repair. With the help of benevolence, medical organizations can easily accept to re-engage with individuals' doctors (John Benson) after trust violation. This shows that apology and justification are a good combination factor that can be used for repairing individual trust in organizations.

More also, this study shows that the verification of Hypotheses 2 and 4 confirmed that competence-based trust had an important moderating effect on the positive relationship between benevolence-based trust and trust repair. In this case, competence could be regarded as a determining factor of repairing trust that has been violated.
\end{abstract}

Key words: Trust, Trust Repair, Competence, Benevolence, Justification, Apology

DOI: $10.7176 / \mathrm{JMCR} / 63-05$

Publication date: December $31^{\text {st }} 2019$

\section{Introduction}

Trust is a social construct that is present in the day-to-day routine of humans. In fact, every time a person needs to interact with, delegate to, or rely on the intentions of another individual, group, or thing, a decision about trust is made (Dai \& Wu, 2015). Trust can generate favorable bargaining, advance individual friendships, and negotiation situations, ease transaction costs between individuals (Yu, Mai, Tsai, \& Dai, 2018), reduce perceptions of risk and insecurity (Fuoli, van de Weijer, \& Paradis, 2017), maintain customer satisfaction and loyalty, and ensure successful sustained relationship (Seeger, Neben, \& Heinzl, 2017), and promote collaboration and teamwork (Guinalíu \& Jordán, 2016; Jenner \& Oprescu, 2016).

Nonetheless, trust is at risk, fragile, and relatively vulnerable since it involves both transaction costs and emotional cultivation (Cui, Zhang, Peng, \& Chu, 2018; Kim, Cooper, Dirks, \& Ferrin, 2013). On occasion, organizations are faced with situations that threaten organizational legitimacy (Kunnel \& Quandt, 2016). Stories of corrupt practices (Eberl, Geiger, \& Aßländer, 2015), negative publicity (Cao, Shi, \& Yin, 2014), product failure (Tomlinson \& Mayer, 2009).

Many studies have been carried out on trust repair under organizational settings, causes of trust violations and some most effective remedies to these trust violations. Scholars propose several ways to repair trust including apologies (Ehrismann \& Stegwee, 2015; Kunnel \& Quandt, 2016), denials (Kim et al., 2013), promises, reticence (Schniter, Sheremeta, \& Sznycer, 2013), justification (Kim \& Harmon, 2014), excuses (Brühl, Basel, \& 
Kury, 2018), compensation (Cui et al., 2018), all important acts such as regulation, penance, and reparation and other verbal responses (Simon \& Jiang, 2017). Bachmann, Gillespie, \& Priem (2015) proposed that analysis of trust repair must take into consideration whether the violation was based on ability, benevolence, or integrity.

Cui et al. (2018) concluded in their analysis that trust would be more effectively restored when the mistrusted parties apologize with an external attribution for infringements of trust based on credibility, whereas apologies with an internal attribution are the best response to infringements of trust based on competence. Bachmann et al. (2015) and other studies provide useful insights into the importance of understanding the cause of an organizational trust violation in order to apply the appropriate measures for repairing that trust.

However, combination of justification and apology as a means of repairing trust violation has not been effectively studied. This led the authors to adopt the causal attribution theory of (Tomlinson \& Mayer, 2009). This study thus investigates how organizations repair competence-based and benevolence-based trust violations using apology and justification. Our objective is to develop and test hypotheses that explore how competencebased and benevolence-based trust violations can be repaired through apology and justification in the case of a medical foundation.

\section{Theoretical background and hypotheses development}

\subsection{Organizational trust, trust repair, trust violations,}

\subsubsection{Organizational Trust}

Trust research spans a broad range of academic fields due to the vital role that trust plays in society. Trust is a broad and complex, multidimensional construct, and always originates from individuals, the target of trust maybe either another person(Ma et al., 2018; Mayer \& Tomlinson, 2009), technological artifacts (Chopra \& Wallace, 2003; Nickel, Franssen, \& Kroes, 2010), or organizations (Peter H Kim, Kurt T Dirks, \& Cecily Cooper, 2009). This makes it notoriously complex to define (Stewgee, 2015) making it difficult to operationalize, measure, and interpret (Simpson, 2007). Regardless, Rousseau et al. (1998) defined trust as the mental state to accept liability based on positive prospect of the intensions or actions of another (Yubao Cui, 2018). This study focuses on individual trust in organizational setting where benevolence and competence-based trust has been violated.

Earlier research by (Mayer, Roger C.; Davis, 1995)indicated that trust involves risk, if we trust others, we do so in the assumption that they will act in a way that is beneficial and not detrimental to us. This belief helps in the evaluation of the other party's trustworthiness. Trustworthiness and trust are interconnected but with different concepts. Trustworthiness is an essential predecessor of trust; it involves a positive potential towards the trusted party and provides a basis for trusting them (Mayer, Roger C.; Davis, 1995). We may divide the principle of trust into two fundamental, components based on the above distinctions: i. trusting intensions and ii. Trusting beliefs (Weitzl, 2016). Trusting intensions involves the ability of trustees to become vulnerable in a risk involving circumstance to the actions of another person or organization. On the other hand, trusting beliefs are the assumptions of trustors' about the trustworthiness of the other party's. Trusting beliefs inform and influence the trusting intensions of individuals. The more trustworthy people or business appear, the more willing the trustor is to trust them and engage in risk-taking behavior (Matteo Fuoli, 2017).

In a bond with a specific other party, perceptions of three characteristics of the party will dominate the trustor's assessment of the party's trustworthiness. (1) Ability (competence): the extent to which the party is deemed to have skills and competencies in the trustor's field of interest. (2) Benevolence: the extent to which the party is deemed to yearn to do positive things for the trustor (3) Integrity: means that the party adheres to a set of values that the trustor considers acceptable. In turn, these three factors will lead to trust. After taking a risk with the trustee, the trustor will examine the outcomes (Tomlinson, 2009). Their relative importance of these, depends on the context and the relationship (Mayer and Davis, 1999); in addition, it has been shown that different stakeholder groups prioritize different components of trustworthiness based on the type of vulnerabilities they face (Matteo Fuoli, 2017).

\subsubsection{Repairing trust}

To restore trust following a perceived violation, the violator will need to take a reparative actions to improve the trustor's trusting beliefs and intentions (Kim H., Cooper D., Ferrin L., \& Dirks T., 2004). Communication is the most important means through which trust repair attempts are carried out. It plays a particularly important role in organizational trust repair, given the relative un-observability of companies' behavior (Fuoli et al., 2017). Recent studies have focused primarily on the role of apologies (Bagdasarov, Connelly, \& Johnson, 2019; Ma et al., 2018). Apology and denial are two of the most fundamental and common strategies for remedying verbal trust repair strategies ((Kim H. et al., 2004). However, in this study, we investigate Apology and justification as mechanisms for repairing individual trust in organizations.

\subsubsection{Justification}

Instead of lessening their responsibility, individuals may accept responsibility while attempting to reframe their behavior as in accordance with some type of superordinate goal or value, or by providing a more positive 
interpretation of the negative outcome (Kim \& Harmon, 2014; Waddock \& Steckler, 2016; Weitzl, 2016). Trustees may attempt to convince trustors to reassess the magnitude or nature of the transgression itself (Schniter et al., 2013).

This type of account provides a justification (Kim \& Harmon, 2014) for behavior that is initially perceived negatively by pointing to reasons that it is legitimate and consistent with moral values. In effect, this account serves the purpose of making the action seem less negative or in a way even positive. Justifications not only involve the accepting responsibility but also proves that the act in question was appropriate owing situation at hand (Bozic, 2017).

Subsequently, the trustee may be able to change the degree to which the trustor finds the conduct to be unjust by explaining the conduct in some way. To the degree that trustors respect the purpose underlined by the trustee's justification, trustors should consider the incident fairer than they might have initially supposed, and thus show greater confidence toward that party than if the justification had not been communicated (Pavlou, 2018). In most situation therefore, justifications refer the trustor to a situational factor, such as a rules and regulations which the trustor may not have known but which represents a good and reasonable purpose when taken into consideration (Kim \& Harmon, 2014).

Although the possible value of justifications has been recommended by the broader literature on social accounts (Manley, 2013) and distributive justice (Hadi A. A L-Abr row, Mohammad Shaker Ardakani, Alireza harooni, \& Hamidreza Moghaddam pour, 2013), as well as recent trust repair theory (Kim et al., 2013), their implications for trust repair after it has been violated remains empirically unexplored. Kim \& Harmon (2014) explore how attempts to explain a transgression as an attempt to address problems of justice, fairness, or need would affect the implications of an apology after a breach of trust, and how that would depend on the intended recipient.

Although combining a justification with an apology tended to obtain greater trust in respect of an apology alone when the violation benefited the other party, it was not effective when the violation benefited the violator. (Kim \& Harmon, 2014). W. Shu, Chen, Lin, \& Chen (2018), found that people were more likely to approve negative actions when it was clarified that the action was the result of good intentions rather than bad ones. Kramer et al. (2012) study of organizational actions in the California cattle industry observed that efforts to justify controversial actions by referencing normative and socially endorsed organizational practices (e.g. federally approved guidelines) provided an effective means of managing organizational legitimacy.

The effectiveness of a justification will depend on the violation type.

Hypothesis 1a: After negative allegations about John Benson's services, justification had a positively relationship with Trust Repair.

Hypothesis 1b: After negative allegations about John Benson's services, apology had a positive relationship with Trust Repair.

\subsubsection{Apology}

An apology conveys declaration acknowledges both guilt and remorse for the infringement and may also express a willingness to resolve and continue the relationship. (Cao et al., 2014; Kim et al., 2013; Schniter et al., 2013)

Tomlinson \& Mayer (2009) classified the type of apology into three categories: one type is a "no-apology" response without ever making an explicit apology to placate the victim; the second type attributes the cause of the violation to internal factors, and the third type attributes the violation to external causes.

More specifically, internal attribution apology is one which acknowledges that the violation is caused by the short comings and limitation of the perpetuator, while an external attribution apology is one that blames external causes (e.g., circumstances, other entities) for the violation. An apology with internal attributions may be more successful in fostering the desire to resolve as the perpetuator takes more personal responsibility for the breach rather than attempting to shift the blame. Those who make excuses to minimize personal responsibility can seriously compromise their reputation and character in the eyes of others (Cui et al., 2018). Following Kim et al. (2013), Apology is described here as a statement acknowledging and regretting the fault of the accused party for the infringement. Past apology research stressed the positive role of apology in enhancing the views of a company's shareholders after a crisis (Cao et al., 2014; Kim et al., 2013; Schniter et al., 2013). An apology signifies redemption (Schniter et al., 2013); it means the company, individual or group have learned their lesson and are dedicated in the future to avoid similar violations. It can help to alleviate the frustration of people and change their attitudes in a more positive direction (Ma et al., 2018). A number of experimental studies on the comparative effectiveness of different crisis response strategies, including apology and justification, have been conducted in crisis communication research. Except for two studies that found no significant differences between the two strategies (Bagdasarov et al., 2019; Kim \& Harmon, 2014), previous experiments show that apology outperforms denial in repairing a company's image in the wake of a crisis (Cao et al., 2014; Kim et al., 2013; Schniter et al., 2013).

However, these studies mainly focus on corporate and individual image or reputation

Hypothesis 2: After negative allegations about John Benson's services, competence-based trust has a positive 
effect on Trust Repair

\subsubsection{Trust violations}

A breach of trust takes place when evidence disconfirms strong, optimistic assumptions about another's actions and redefines the nature of the relationship in the injured party's mind. (Tomlinson \& Mayer, 2009). Weiner (2008) causal attribution theory facilitates understanding into how trust is damaged and the processes that take place in updating perceptions of trustworthiness. In his theory the perception of a negative outcome leads to a general emotional reaction of displeasure, which causes the individual to identify the outcome's cause (Mayer \& Tomlinson, 2009). Negative emotions such as the harmed individual's disappointment, frustration, anger and outrage following a violation were well documented (Ma et al., 2018). However, individuals do not experience the full range of these emotions when considering the feelings of others who have had their trust violated (Kramer et al., 2012).

Therefore, violation with personal consequences (i.e. results related to oneself) can elicit stronger reactions than organizational consequences (i.e. results relevant to the organization as a whole than one individual) (Bagdasarov et al., 2019). The perceived cause, however, is referred to as causal ascription depending on whether the breach of confidence involves matters of competence, integrity or benevolence. Cao et al. (2014) found in their analysis of competency-based and integrity-based violation of trust that individuals tend to weigh positive information about competency more heavily than negative information about competency and tend to weigh negative information about integrity more heavily than positive information. (Cui et al., 2018). Nevertheless, the actions of the trustee may also weaken his or her sense of benevolence when viewed as evidence of disrespect for the well-being and interests of the trustor. (Fuoli et al., 2017). An example of this is the 20 April 2010 Deepwater Horizon oil spill caused by the explosion and sinking of a British Petroleum (BP) offshore oil platform in the Gulf of Mexico. Efforts to show benevolence were hampered by the controversial public statements of its president and CEO, Tony Hayward. In fact, in an interview at the height of the crisis, the now notorious statement' I want my life back' pointed to the suggestion that the CEO and, by implication, BO put other interests ahead of the crisis resolution (Fuoli \& Paradis, 2014).

Hypothesis 3a: After negative allegations about John Benson's services, Benevolence based trust has a mediating effect on Justification

Hypothesis 3b: After negative allegations about John Benson's services, Benevolence based trust has a mediating effect on Apology

\subsubsection{Intentions to re-engage}

The reasoned action theory by (Pavlou, 2018) that behavioral motives, which are the immediate context to actions, are a feature of sound knowledge or assumptions about the probability that when a person performs a particular behavior, it will lead to specific results. The theory splits the previous beliefs into two conceptually distinct sets of situational intentions: behavioral and normative. Behavioral beliefs are believed to be the fundamental impact on the attitude of an individual towards behavior performance, while normative beliefs affect the subjective norm of the individual regarding behavior performance. Therefore, either through attitudes and/or through social norms, knowledge or salient beliefs influences intentions and subsequent actions. The theory of planned behavior incorporates perceived behavioral regulation as an exogenous factor that through actions has a direct effect on behavior as well as an indirect effect on behavior. Trust needs knowledge and action intent. Expressions of trust not followed by behavioral intent suggest that the relationship is weak. (Fuoli et al., 2017). From a firm's perspective, if its image and reputation have been damaged by negative publicity, repairing trust will enhance the customers' tolerance and restore engagement intentions (Wolfe \& Blithe, 2015). Thus, the following hypotheses are suggested:

Hypotheses 4: Competence-based trust has a moderating effect on the relationship between Benevolence based trust and Trust Repair.

Research Model

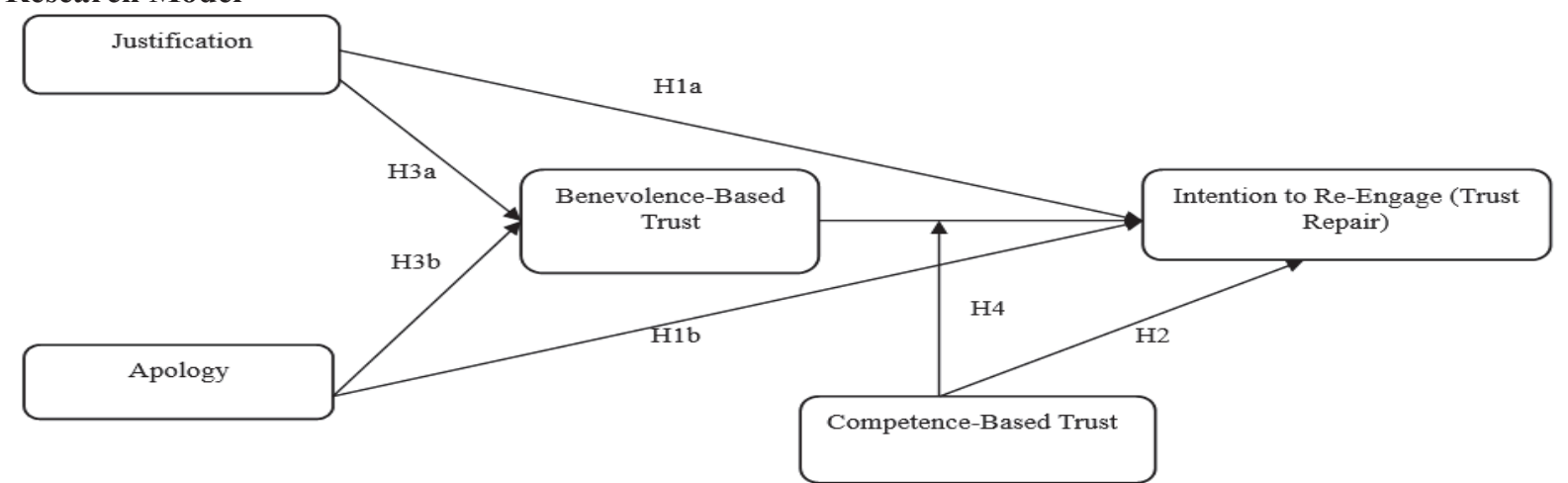

Source: Causal Attribution Model (Tomlinson \& Mayer, 2009) 


\section{Methodology}

The foremost objective of this section is to investigate how trust could be repaired when the trust violator adopts the strategy of apology and justification. The research techniques provide a logical and systematic approach to the investigation, which links to the comprehensive framework of the analysis unit, data collection techniques, sample concentration, interpretation techniques and analysis plan. Scenario-based experiments were performed to test the hypotheses mentioned above and to assess the results of trust repair strategy following suspected violations of trust based on competence and benevolence. The experiments involved a $2 \times 2$ between-subjects design with trust violation type $\mathbf{x} \mathbf{2}$ (benevolence vs competence) and trust repair strategies $\mathbf{x} 2$ (apology vs justification).

\subsection{Questionnaires}

The survey consisted of four parts. The first part describes the objectives of the study and the socio-demography of the respondents followed by a general depiction of the fictitious private medical foundation. The issues showing that John Benson didn't care about human life and that he didn't know his job well as a medical practitioner (benevolence-based vs competence-based trust violation).

The participants played the role of patients who in one way or the other were in the hospital at the time John Benson was accused or who heard the rumor about the said incident. The respondents were given a scenario describing how John Benson reacted to handling the accusation regarding the apology and justification. After that, they answered a series of questions concerning key constructs and items for manipulation check.

\section{Manipulations}

In keeping with our $2 \times 2$ experimental design, four variations of the scenario are presented in the questionnaire. Each version contained an identical general depiction of the focal individual and the rumor that he extracted blood from a parent without checking his blood pressure due to incompetence and lack of human feelings. The other scenario sections comprising the three manipulations which defined the various scenario conditions for violation forms and techniques for repairing them.

\section{Violation type and response}

The breach of trust was framed either on the basis of benevolence or competence. The violation was defined in such a way that it was in line with the theoretical concepts of benevolence and integrity previously presented in the article (Kim H. et al., 2004). In both conditions, the job applicant was accused of killing an innocent man due to his carelessness and for not having human feelings. In the competence condition, a fictitious medical practitioner (John Benson) of a private hospital name SAVE THE CHILD FOUNDATION takes blood from a patient's father whose child was almost losing his life to shortage of blood as a result of a motor accident. The doctor collected blood from the man without testing his blood pressure and the man eventually dies. He was accused of incompetence as he didn't do his job well, he should have known he had to test the patient before extracting his blood (competence-based trust).

In the benevolence condition, he was also accused of being so much concerned about making money and not taking care of human life and was thus fired from the hospital. He goes seeking for another job in another hospital but they are finding it difficult to trust him again due to the rumor that was spreading about him.

He apologizes for administering the blood extraction from the patient's father without doing several tests and accepts his responsibility after and promised never to do it again, and stated that the hospital would not have any concerns about her competence/benevolence if he were hired.

He also justifies that he did that not because of money but because he wanted to save the child's life which was at stake and because of the pressure and tension from the child's parent for fear of death, he forgot to test the blood pressure (BP) of the child's father.

\section{Participants}

Data were collected via offline survey by using random sampling technique in the Eastern Region of Cameroon during the second quarter of the year 2019. The questionnaires were distributed to 304 participants. Out of 304 individuals, $135(44.4 \%)$ were male, and $169(55.6 \%)$ were female. The response rate in female was high due to the fact that they are the mothers of the affected children. The theme and objectives of this study were explained to the respondents before the questionnaires were administered. Participants were informed in the instructions that participation in the study is voluntary, that the questionnaire is anonymous (no names required but demographic information required), and that by responding to the survey they are giving their consent for their data to be used for the purposes of the study. Completing the questionnaire took just about 10 minutes. The respondents were recruited in exchange for a bottle of juice to motivate them in answering the questions, after which the participants were debriefed and thanked for their participation. In addition, majority of the respondents were aged between $30-39$ years $143(44.0 \%) .32(10.0 \%)$ respondents had secondary school certificate (SSC), 50 (16.4\%) had professional diploma (PD), $129(42.4 \%)$ had bachelor's degree (BSc), 76 (25.04\%) had master's $(\mathrm{MSc})$ and $17(5.6 \%)$ had doctorate degree $(\mathrm{PhD})$. A total of $117(38.5 \%)$ respondents were unemployed, 68 $(22.4 \%)$ were intern, $48(15.8 \%)$ were part-time worker, 58 (19.1\%) were full-time worker and $13(4.3 \%)$ were 
business owners. See Table 1.

Table 1: Demographics of respondents

\begin{tabular}{|llll|}
\hline Category & & Frequency & Percentage \% \\
\hline Gender & Male & 135 & 41.4 \\
& Female & 169 & 55.6 \\
\hline Age & $18-29$ years & 118 & 33.8 \\
& $30-39$ years & 143 & 47.0 \\
& $40-49$ years & 41 & 13.5 \\
& $50-59$ years & 2 & 7.0 \\
& 60-above & 0 & 0 \\
\hline Level of education & Secondary school certificate & 32 & 10.5 \\
& Professional diploma & 50 & 16.4 \\
& Bachelor's degree & 129 & 42.4 \\
& Master's degree & 76 & 25.0 \\
& PhD & 17 & 5.6 \\
\hline Occupation & Unemployed & 117 & 38.5 \\
& Intern & 68 & 22.4 \\
& Part-time & 48 & 15.8 \\
& Full-time & 58 & 19.1 \\
& Business owner & 13 & 4.3 \\
\hline
\end{tabular}

Manipulation checks:

Participants responded to two manipulation test questions designed to determine whether they understood the categorically different experimental conditions they were assigned to. Each of the manipulation checks were multiple choice questions in which participants were provided with several answer options. On the first administration of the questionnaire, two manipulation check questions were included regarding whether participants understood the violation and response. For instance, participants were asked

1. What does this accusation bring into question?

a. John Benson's competence

b. John Benson's benevolence

2. What was John Benson's response to the accusation?

a. John Benson's responded with an apology

b. John Benson's responded with a justification

Participants replied to some dependent measures after answering the two manipulation test questions. (See Appendix).

\section{Dependent measures}

Since most previous research suggested that the perceived trustworthiness of the customer is ultimately determined by that individual's consumer trust (Pavlou, 2018; Srivastava, Chandra, \& Theng, 2010), we will simultaneously analyze perceived trustworthiness and trust. Our survey's perceived trustworthiness measures (competence and benevolence) after the individual has adopted efforts to repair trust were adapted from (Jucks \& Thon, 2017) who revised the measures from other literature (Kim H. et al., 2004) to suit the health environment after the person had made efforts to restore trust. Consumer intention to re-engage was measured by seven items, ("Generally speaking, I trust John Benson", “John Benson is reliable", "John Benson is dependable", "I wouldn’t let John Benson have any influence over issues that are important to me", "I would engage with John Benson to solve a problem that was critical to me i.e. health-related problems", "I would recommend John Benson to friends, neighbors, and relatives" and "I feel very confident about the intentions of John Benson" (Cui et al., 2018; Goyal, Sergi, \& Esposito, 2013; Kim et al., 2013; Mayer, Roger C.; Davis, 1995; Peter H Kim et al., 2009). Every single elements have been assessed on a Likert scale of 5 points (1 strongly accepted, 5 strongly disagreed) and can be seen in Table 2. 


\begin{tabular}{|c|c|c|}
\hline Variables & Items & Sources \\
\hline Justification & $\begin{array}{l}\text { 1. John Benson has provided evidence to prove its products } \\
\text { are now up to international quality standard. } \\
2 \text {. John Benson has provided evidence to prove its current } \\
\text { quality of its products. } \\
3 \text {. John Benson has provided evidence to prove its other } \\
\text { products to be qualified. } \\
\text { 4. John Benson has proven its innocence by justifying that its } \\
\text { products are not to harm its consumers. }\end{array}$ & (Cao et al., 2014) \\
\hline Apology & $\begin{array}{l}\text { 1. John Benson has made an obvious apology to the victims } \\
\text { and the public. } \\
2 \text { John Benson has taken consumers emotions into } \\
\text { consideration. } \\
\text { 3. John Benson has taken responsibility of its action. } \\
\text { 4. John Benson has apologized for its carelessness. }\end{array}$ & (Cao et al., 2014) \\
\hline $\begin{array}{l}\text { Benevolence } \\
\text { Based Trust }\end{array}$ & $\begin{array}{l}\text { 1. John Benson seems very concerned about the welfare of } \\
\text { people. } \\
2 \text {. The needs and desires of people seem to be very important } \\
\text { to John Benson } \\
3 \text {. John Benson seems to be interested in the well-being of } \\
\text { people, not just themselves. } \\
4 \text {. Judging from John Benson's response, I believe that when } \\
\text { patients have problems, the social enterprise will respond } \\
\text { constructively and with care. } \\
5 \text {. John Benson treats patients with respect when responding } \\
\text { to negative publicity. }\end{array}$ & $\begin{array}{l}\text { Adapted from Mayer \& } \\
\text { Davis (1999) } \\
\text { Adapted from Kim et al. } \\
\text { (2007) } \\
\text { Adapted from Cui et al. } \\
\text { (2018) }\end{array}$ \\
\hline $\begin{array}{l}\text { Competence } \\
\text { Based Trust }\end{array}$ & $\begin{array}{l}\text { 1.John Benson is very capable of performing her job, } \\
\text { 2.John Benson has much knowledge about his job } \\
\text { 3.I feel very confident in John Benson's skills. } \\
\text { 4.Given John Benson's response, I believe he can avoid repetition } \\
\text { of such problems }\end{array}$ & $\begin{array}{l}\text { Xie and Peng (2009) } \\
\text { Adapted from Kim et al. } \\
\text { (2004) } \\
\text { Adopted from } \\
\text { Sirdeshmukh et al. (2002) }\end{array}$ \\
\hline $\begin{array}{l}\text { Intention to } \\
\text { Re-Engage } \\
\text { (Trust } \\
\text { Repair) }\end{array}$ & $\begin{array}{l}\text { 1. Generally speaking, I trust John Benson. } \\
\text { 2. Generally speaking, John Benson is reliable. } \\
\text { 3. Generally speaking, John Benson is dependable. } \\
\text { 4. I wouldn't let John Benson have any influence over issues } \\
\text { that are important to me. } \\
\text { 5. I would engage with John Benson to solve a problem that } \\
\text { was critical to me i.e. environmental or health-related. } \\
6 . \quad \text { I would recommend John Benson to friends, neighbors, } \\
\text { and relatives. } \\
\text { 7. I feel very confident about the intentions of John Benson }\end{array}$ & $\begin{array}{l}\text { Adapted from Choi \& } \\
\text { Kim (2013) } \\
\text { Adapted from Mayer \& } \\
\text { Davis (1999) } \\
\text { Adapted from Kim et al. } \\
\text { (2007) } \\
\text { Adapted from Cui et al. } \\
\text { (2018) }\end{array}$ \\
\hline
\end{tabular}

\section{Pilot study}

We conducted a pilot study before the data collection. The questionnaires were given to 60 people in Cameroon. To assess the accuracy and validity of the results, the exploratory factor analysis (EFA) was performed. The results showed that the measurements, accuracy and validity was quite good.

\section{Data Analysis}

Data was analyzed using SPSS 23 \& AMOS 21 using the structural equation modeling technique. Next, we used the descriptive method to find the respondents ' demographic information, mean, standard deviation for all variables. Furthermore, to analyze the relationships between the constructs, Pearson correlation was used. Fourth, we carried out exploratory factor analysis (EFA) to discuss the reduction of dimensions of items and to analyze the accuracy, convergent validity and discriminating validity of the model of the research. We used Cronbach's alpha and composite reliability to test the reliability of the model. The convergent validity has been tested to determine the factor loadings, composite reliability and average variance derived from each variable. Simultaneously, we tested the discriminate validity of each construct by taking the square root of AVE values. In addition, confirmatory factor analysis (CFA) was used to confirm the fit indices of our measurement system, as it is the most effective and accepted technique for validating the measurement model. Lastly, regression analysis was carried out using SPSS IBM 23 to test whether benevolence and competence-based trust mediate and moderate the relationships between the independent variables (apology and justification) with the aim of 
restoring trust in John Benson by the medical foundations.

\section{Results of validity and reliability}

To determine the validity and factor loading (FL) of each product, we used exploratory factor analysis (EFA). In particular, the loading of each item above the lower cut-off value of 0.5 was found to have no cross-loading effect and recommended for further study. (Hu \& Bentler, 1999). By using the main element approach with varimax rotation, we performed EFA and suppressed values below 0.30. Table 3 shows the factor loading of all items. All factor loadings are in the range of 0.57 and 0.93 while the recommended values should be substantial and exceed than 0.7. We also looked at the extracted average variance (AVE) to ensure reliability and convergent validity of products. All AVE values were higher in our data than the recommended minimum threshold of 0.50 , which suggests that the items met the convergent validity criteria. To measure the reliability of constructs we used composite reliability (CR) and Cronbach's alpha (CA) values. Values of CR and CA are acceptable when it scores greater than 0.7. Table 3 shows that all $\mathrm{CR}$ and CA values exceed 0.7 , verifying measurement reliability (Weitzl, 2016). Discriminate validity is well-known by initially ensuring an indicator's outer loading on a variable is greater than cross-loadings with other variables, and next by ensuring for each variable, the square root of the AVE is higher than the outer correlations (Hair \& Gabriel, 2014). The results show that square root of AVEs is higher than outer correlations and all outer loading are greater than crossloadings for each construct and the (Table 4). The results verify discriminate validity. Overall, the findings of the presented measurement method show high reliability and validity. In addition, the structural model was tested using IBM AMOS 21 for the validated steps. The overall fitness indices are within the agreed scope of confirmatory factor analysis (CFA). The value of CMIN/df is 2.613 which is within the preferred range of CMIN to be ranged between 1 and 3. Moreover, Fitness indice include the indices of relative (NFI, IFI, and TLI) and non-centrality indices (RMSEA and CFI) (Hu \& Bentler, 1999). We found NFI 0.958, IFI 0.969 and TLI 0.972 which supporting that the values should be higher than 0.95 . Regarding the non-centrality indices, the values of RMSEA and CFI are .073 and 0.968 respectively. The finding supports previous literature that both values of RMSEA and CFI should be $<0.08$ and $>0.90$ respectively (Hu \& Bentler, 1999). Therefore, the outcomes show a valid model fit as shown in Table 3.

Table 3: Validity and reliability of constructs

\begin{tabular}{|c|c|c|c|c|c|}
\hline Variable & Items & Factor loading & Cronbach's Alpha & AVE & CR \\
\hline Justification & $\begin{array}{l}\mathrm{J} 1 \\
\mathrm{~J} 2 \\
\mathrm{~J} 3 \\
\mathrm{~J} 4 \\
\end{array}$ & $\begin{array}{l}.82 \\
.85 \\
.83 \\
.83\end{array}$ & .89 & .69 & .90 \\
\hline Apology & $\begin{array}{l}\text { AP1 } \\
\text { AP3 } \\
\text { AP3 } \\
\text { AP4 }\end{array}$ & $\begin{array}{l}.82 \\
.84 \\
.83 \\
.57 \\
\end{array}$ & .85 & .60 & .85 \\
\hline Benevolence based trust & $\begin{array}{l}\text { BBT1 } \\
\text { BBT2 } \\
\text { BBT3 } \\
\text { BBT4 } \\
\text { BBT5 }\end{array}$ & $\begin{array}{l}.91 \\
.93 \\
.92 \\
.93 \\
.92 \\
\end{array}$ & .96 & .85 & .97 \\
\hline Competence based trust & $\begin{array}{l}\text { CBT1 } \\
\text { CBT2 } \\
\text { CBT3 } \\
\text { CBT4 }\end{array}$ & $\begin{array}{l}.89 \\
.90 \\
.92 \\
.87\end{array}$ & .94 & .80 & .94 \\
\hline Intention to re-engage & $\begin{array}{l}\text { TR1 } \\
\text { TR2 } \\
\text { TR3 } \\
\text { TR4 } \\
\text { TR5 } \\
\text { TR6 } \\
\text { TR7 }\end{array}$ & $\begin{array}{l}.79 \\
.81 \\
.77 \\
.85 \\
.73 \\
.80 \\
.79\end{array}$ & .89 & .92 & .85 \\
\hline
\end{tabular}

Note: $\mathrm{J}=$ Justification, AP $=$ Apology, BBT $=$ Benevolence based trust, $\mathrm{CBT}=$ Competence based trust and TR $=$ Intention to re-engage (Trust repair)

\section{Mean standard deviation and correlations}

Table 4 presents the means, standard deviations (SD), and correlations results of the study variables including justification, apology, benevolence based trust, competence based trust and intention to re-engage (trust repair). As predicted, justification was significantly correlated to Apology (AP) $\left(0.659^{* *}, \mathrm{P}<.01\right)$, benevolence based trust $(\mathrm{BBT})\left(0.535^{* *}, \mathrm{P}<.01\right)$, competence based trust $(\mathrm{CBT})\left(0.462^{* *}, \mathrm{p}<.01\right)$ and trust repair $(\mathrm{TR})\left(0.171^{* *}\right.$, 
$\mathrm{p}<.01)$. This shows that justification plays a critical role in restoring consumer's intentions to re-engage (trust repair). In addition, Apology (AP) significantly correlates with Benevolence-based trust (BBT) (0.660**, p $<.01)$, Competence based trust (CBT) $\left(0.468^{* *}, \mathrm{p}<.01\right)$ and Trust repair $(\mathrm{TR})\left(0.265^{* *}, \mathrm{p}<.01\right)$. Moreover, Benevolence-based trust (BBT) significantly have a relationship with Competence Based Trust (CBT) $\left(0.605^{* *}\right.$, $\mathrm{p}<.01)$ and Trust repair $(\mathrm{TR})\left(0.148^{* *}, \mathrm{p}<.01\right)$. Competence-based trust $(\mathrm{CBT})$ also correlates significantly with Trust repair $(\mathrm{TR})\left(0.376^{* *}, \mathrm{p}<.01\right)$. Therefore, benevolence based trust $(\mathrm{BBT})$ and Competence based trust (CBT) serves as mediators and moderators in enhancing consumer's re-engagement intentions respectively.

Table 4: Mean, standard deviation and correlations.

\begin{tabular}{|l|lllllll|}
\hline & MEAN & SD & J & AP & BBT & CBT & TR \\
\hline J & 5.16 & 1.31 & $\mathbf{( 0 . 8 3 )}$ & & & & \\
AP & 5.07 & 1.6 & $0.659^{* *}$ & $\mathbf{( 0 . 7 7 )}$ & & & \\
BBT & 6.7 & 1.8 & $0.535^{* *}$ & $0.660^{* *}$ & $\mathbf{( 0 . 9 2 )}$ & & \\
CBT & 5.2 & 1.4 & $0.462^{* *}$ & $0.468^{* *}$ & $0.605^{* *}$ & $\mathbf{( 0 . 8 9 )}$ & \\
TR & 1.7 & 0.5 & $0.171^{* *}$ & $0.265^{* *}$ & $0.148^{* *}$ & $0.376^{* *}$ & $\mathbf{( 0 . 7 9 )}$ \\
\hline
\end{tabular}

**. Correlation is significant at the 0.01 level (2-tailed). Note: $\mathrm{J}=$ (Justification), $\mathrm{A}=($ Apology), BBT= (benevolence-based trust), $\mathrm{CBT}=($ Competence-based-trust) and $\mathrm{TR}=$ (Trust repair). The bold values in the parentheses are the discriminate validity of the study variables.

Table 5: Fitness indices for the proposed Model

\begin{tabular}{|l|l|l|}
\hline Fitness indices & Observed values in CFA & Recommended values \\
\hline CMIN/df & 2.613 & Less than 3.0 (Hu \& Bentler, 1999) \\
NFI & .958 & Above .90 (Tarka, 2018) \\
IFI & .969 & Above .95 (Hu \& Bentler, 1999) \\
TLI & .972 & Above .95 (Hu \& Bentler, 1999) \\
CFI & .968 & Above .95 (Tarka, 2018) \\
RMSEA & .073 & Less than .08 (Bélanger \& Carter, 2005) \\
\hline
\end{tabular}

Note: *represents $\mathrm{p}<0.05 ; * *$ represents $\mathrm{p}<0.01 ; * * *$ represents $\mathrm{p}<0.001$.

\begin{tabular}{|c|c|c|c|c|c|c|c|c|c|c|c|c|}
\hline Variable`s & $\begin{array}{l}\text { Step } \\
1\end{array}$ & & & $\begin{array}{l}\text { Step } \\
2\end{array}$ & & & $\begin{array}{l}\text { Step } \\
3\end{array}$ & & & $\begin{array}{l}\text { Step } \\
4\end{array}$ & & \\
\hline & $\mathrm{B}$ & $\mathrm{T}$ & VIF & $\mathrm{B}$ & $\mathrm{T}$ & VIF & $\mathrm{B}$ & $\mathrm{T}$ & VIF & $\mathrm{B}$ & $\mathrm{T}$ & VIF \\
\hline (Constant) & 2.15 & $5.58 * * *$ & & 2.41 & $6.82 * * *$ & & 0.65 & $3.43 * * *$ & & 1.89 & $4.86 * * *$ & \\
\hline Gender & 0.21 & $2.28 *$ & 1.05 & 0.18 & 1.93 & 1.07 & 0.03 & 0.57 & 1.07 & 0.16 & 1.76 & 1.07 \\
\hline Age & 0.06 & 0.71 & 2.02 & 0.04 & 0.46 & 2.03 & 0.05 & 1.04 & 2.02 & 0.06 & 0.69 & 2.02 \\
\hline $\begin{array}{l}\text { Level of } \\
\text { education }\end{array}$ & 0.12 & 1.79 & 1.02 & 0.08 & 1.23 & 1.05 & 0.02 & 0.68 & 1.03 & 0.80 & 1.26 & 1.03 \\
\hline Occupation & -0.09 & -1.32 & 2.62 & -0.10 & -1.43 & 2.64 & -0.06 & -1.55 & 2.62 & -0.10 & -1.39 & 2.62 \\
\hline Justification & 0.07 & $3.02 * *$ & 1.03 & & & & & & & & & \\
\hline $\begin{array}{l}\text { Apology } \\
\text { competence based } \\
\text { trust }\end{array}$ & & & & 0.09 & $4.78 * * *$ & 1.08 & 0.13 & $7.04 * * *$ & 1.04 & & & \\
\hline $\begin{array}{l}\text { Benevolence } \\
\text { based trust }\end{array}$ & & & & & & & & & & 0.04 & $2.59 * * *$ & 1.05 \\
\hline
\end{tabular}

Table 7: Tests of the mediating effects of benevolence-based trust

\begin{tabular}{|c|c|c|c|c|c|c|c|c|c|c|c|c|}
\hline & $\begin{array}{l}\text { Step } \\
\text { 1a }\end{array}$ & & & Step 2 & & & $\begin{array}{l}\text { Step } \\
3 b\end{array}$ & & & $\begin{array}{l}\text { Step } \\
4 b\end{array}$ & & \\
\hline Variables & $\mathrm{B}$ & $\mathrm{T}$ & VIF & B & $\mathrm{T}$ & VIF & B & $\mathrm{T}$ & VIF & B & $\mathrm{T}$ & VIF \\
\hline (Constant) & 1.24 & $5.13 * * *$ & & 1.86 & $8.24 * * *$ & & 1.81 & $4.54 * * *$ & & 1.88 & $4.84 * * *$ & \\
\hline Gender & 0.16 & $2.69 * *$ & 1.05 & 0.08 & 1.32 & 1.07 & 0.17 & 1.81 & 1.08 & 0.16 & 1.71 & 1.07 \\
\hline Age & 0.01 & 0.11 & 2.02 & -0.05 & -0.87 & 2.03 & 0.06 & 0.70 & 2.02 & 0.05 & 0.63 & 2.04 \\
\hline $\begin{array}{ll}\text { Level } & \text { of } \\
\text { education }\end{array}$ & 0.11 & $2.63 * *$ & 1.02 & 0.02 & 0.42 & 1.05 & 0.09 & 1.34 & 1.04 & 0.08 & 1.17 & 1.05 \\
\hline occupation & 0.02 & 0.39 & 2.61 & -0.01 & -0.11 & 2.64 & -0.10 & -1.40 & 2.62 & -0.10 & -1.43 & 2.64 \\
\hline Justification & 0.67 & $11.01 * * *$ & 1.03 & & & & 0.05 & 1.93 & 1.66 & & & \\
\hline Apology & & & & 0.78 & $15.27 * * *$ & 1.08 & & & & 0.09 & 4.02 & 1.68 \\
\hline $\begin{array}{l}\text { Benevolence } \\
\text { based trust }\end{array}$ & & & & & & & 0.04 & $2.59 * *$ & 1.69 & 0.08 & $2.06 * *$ & 1.63 \\
\hline
\end{tabular}

Note. $*$ represents $\mathrm{p}<0.05$; ** represents $\mathrm{p}<0.01$; *** represents $\mathrm{p}<0.001$. ${ }^{\text {a }}$ Represents benevolence-based trust as dependent variable. $\quad{ }^{b}$ represents trust repair as dependent variable. 
Table 8: Tests of the moderating effects of competence based trust

\begin{tabular}{|c|c|c|c|c|c|c|}
\hline \multirow[t]{2}{*}{ Variables } & $\begin{array}{c}\text { Step } \\
1\end{array}$ & \multicolumn{5}{|c|}{$\begin{array}{c}\text { Step } \\
2\end{array}$} \\
\hline & $\mathrm{B}$ & $\mathrm{T}$ & VIF & $\mathrm{B}$ & $\mathrm{T}$ & VIF \\
\hline (Constant) & 3.49 & $20.23 * * *$ & & 3.50 & $20.99 * * *$ & \\
\hline Gender & 0.02 & 0.34 & 1.08 & 0.02 & 0.50 & 1.08 \\
\hline Age & 0.05 & 1.05 & 2.02 & 0.04 & 0.97 & 2.03 \\
\hline Level of education & 0.02 & 0.48 & 1.04 & 0.01 & 0.19 & 1.04 \\
\hline Occupation & -0.06 & -1.66 & 2.63 & -0.07 & -1.81 & 2.63 \\
\hline Centralized benevolence-based trust & 0.04 & $2.59 * *$ & 1.11 & 0.09 & $3.45 * *$ & 1.21 \\
\hline Centralized competence-based trust & 0.14 & $7.04 * * *$ & 1.10 & 0.10 & $6.13 * * *$ & 1.18 \\
\hline $\begin{array}{l}\text { Centralized benevolence-based trust } * \text { centralized } \\
\text { competence-based trust }\end{array}$ & & & & 0.16 & $6.77 * * *$ & 1.15 \\
\hline
\end{tabular}

Note: $*$ represents $\mathrm{p}<0.05 ; * *$ represents $\mathrm{p}<0.01 ; * * *$ represents $\mathrm{p}<0.001$.

\section{Regression, Mediation and Moderation Analysis}

Table 6 shows the regression analysis in testing the relationship between the dependent variable and the independent variables. Step 1 indicates that after negative allegations about John Benson's services, justification had a positively significant relationship with Trust Repair. $(B=0.067 ; \mathrm{t}=3.019, \mathrm{p}<0.05)$. H1a was supported.

Step 2, apology was used as the independent variable. After a negative allegation about John Benson's Apology had a significant positive relationship with trust repair $(B=0.09 ; \mathrm{t}=4.78, \mathrm{p}<0.05)$. It shows support for H1b.

From Step 3, when competence was used as the independent variable, we could deduce that after negative allegations about John Benson's services, competence-based trust has a positive effect on Trust Repair $(\mathrm{B}=0.13$; $\mathrm{t}=7.04, \mathrm{p}<0.05)$. H2 was supported.

Step 4, benevolence-based trust had a significant positive relationship with trust repair $(B=0.40 ; t=2.59$, $\mathrm{p}<0.05)$.

The relationship among benevolence based trust, justification and apology were tested. As shown in table 7 step 1a, justification had a significant positive relationship with benevolence based trust $(B=0.67 ; t=11.01$, $\mathrm{p}<0.05)$. Similarly, as shown in step $2 \mathrm{a}$, apology was positively related to benevolence based trust $(\mathrm{B}=0.78$; $\mathrm{t}=15.27, \mathrm{p}<0.05)$.

Trust repair was used as the dependent variable to test the mediating effect of benevolence based trust. As shown in step 4 of table 6 , benevolence based trust had a significant positive relationship with trust repair $(B=0.040 ; t=2.593, p<0.05)$. Therefore, from the comparison between table 6 step 1 and table 7 step $3 b$, the relationship between justification and trust repair became insignificant $(\mathrm{B}=0.051 ; \mathrm{t}=1.93, \mathrm{p}>0.05)$ when benevolence based trust was added to the regression. This change indicated that benevolence based trust had a fully mediating effect on the relationship between justification and trust repair. Thus, H3a was supported.

Similarly, benevolence based trust had a significant positive relationship with trust repair $(\mathrm{B}=0.04 ; \mathrm{t}=2.593$, $\mathrm{p}<0.05)$. Therefore, from the comparison between table 6 step 2 and table 7 step $4 \mathrm{~b}$, the relationship between apology and trust repair became insignificant $(B=0.095 ; \mathrm{t}=4.02, \mathrm{p}>0.05)$ when benevolence based trust was included in the regression.

To test the moderating effect of competence based trust, the value of competence based and benevolence based trust were centralized. Trust repair was used as the dependent variable. As seen in table 8, the values of the VIF were all less than 3 , which signifies that the regression had no significant multi-collinearity. As shown in table 8 step 1, Benevolence based trust and trust repair has a significantly positive relationship ( $\mathrm{B}=0.040$; $\mathrm{t}=2.593, \mathrm{p}<0.05)$. Likewise, competence based trust and trust repair also had a significantly positive relationship $(\mathrm{B}=0.14 ; \mathrm{t}=7.04, \mathrm{p}<0.001)$.

In step 2, the interaction of Benevolence based trust and competence-based trust was added to the regression which was significantly related to trust repair $(B=0.16 ; t=6.77, p<0.001)$. This change indicated that competence-based trust had a significantly and moderating effect on the relationship between benevolence based trust and trust repair, thereby H4 was supported.

\section{Discussion and Conclusion}

In this research, we are interested in examining how to restore individual trust in an institutional setting using apology and justification, with the mediating and moderating impact of trust based on benevolence and competence respectively. Through a scenario questionnaire survey, the study provided support for all of the hypotheses. Hypotheses 1 and 3 focused on the strategies of repairing trust. The relationship among justification, apology and trust repair, and the mediating effect of benevolence based trust, could find support in other causal attribution studies (Mayer \& Tomlinson, 2009) 
The study proposed a conceptual model based on causal attribution theory that individual apology and justification of an act had significant effect on trust violation which subsequently influences the way of repairing the violated trust. "Will justification and apology influence the repair of benevolence and

competence based trust violation?" The research found evidence to support the idea that a proper justification in combination with apology would reduce patients and organizations' negative orientation about the trust violator (John Benson) and enhance their intention to re-engage in a situation where patients and organizations themselves already have a low level of trust on the violator. Compared to previous studies strategies of repairing trust (Cui et al., 2018; Kim et al., 2013), this study distinguishes strategies of repairing trust into justification and apology .

First, there is a positive connection between justification and apology and the intention to re-engage. This depicts that findings of the study reveal that justification and apology have significant positive relationships with benevolence based trust. Similarly, benevolence based trust significantly boosted the intention to re-engage by patients and organization which is a way of repairing trust that has been violated. In this study, benevolence is found to play a mediating role in the relationship between justification, apology and intention to re-engage. Likewise, competence based trust strengthen the relationship between benevolence based trust and intention to re-engage serving as the moderation effect.

In the first hypothesis of our study, the findings show that justification significantly contribute to trust repair. The results are in line with the previous studies that justification of trust violation act goes a long way in ensuring the restoration of the peoples' mindset towards negative orientation against the trust violator (Kim \& Harmon, 2014; Peter H Kim et al., 2009).

Second, in accordance with causal attribution theory, competence based trust also has a positive effect on patients and organizations' intention to re-engage. This study shows that combination of proper strategies can be effective in repairing trust that has been violated, provided there is a clear justification of the said allegation and an apology in a case the accused knows he is guilty.

Lastly, this study shows that the verification of Hypotheses 2 and 4 confirmed that competence-based trust had an important moderating effect on the positive relationship between benevolence based trust and trust repair. In this case, competence could be regarded as a determining factor of repairing trust that has been violated. This also shows that justification and apology are a good combination factor that can be used for repairing individual trust in an organizational setting. Therefore, with benevolence and competence, other medical foundations can easily accept to re-engage with John Benson's services.

\section{References}

Bachmann, R., Gillespie, N., \& Priem, R. (2015). Repairing Trust in Organizations and Institutions: Toward a $\begin{array}{lllll}\text { Conceptual } & \text { Framework. } & \text { Organization } & \text { Studies, } & 36(9),\end{array}$ https://doi.org/10.1177/0170840615599334

Bagdasarov, Z., Connelly, S., \& Johnson, J. F. (2019). Denial and empathy: Partners in employee trust repair? Frontiers in Psychology, 10(JAN), 1-13. https://doi.org/10.3389/fpsyg.2019.00019

Bozic, B. (2017). Consumer trust repair: A critical literature review. European Management Journal, 35(4), 538-547. https://doi.org/10.1016/j.emj.2017.02.007

Brühl, R., Basel, J. S., \& Kury, M. F. (2018). Communication after an integrity-based trust violation: How organizational account giving affects trust. European Management Journal, 36(2), 161-170. https://doi.org/10.1016/j.emj.2017.08.001

Cao, T., Shi, G., \& Yin, Y. (2014). How to repair customer trust of high-risk products after negative publicity. Nankai Business Review International, 5(4), 382-393. https://doi.org/10.1108/NBRI-03-2014-0015

Chopra, K., \& Wallace, W. A. (2003). Trust in electronic environments. Proceedings of the 36th Annual Hawaii International Conference on System Sciences, HICSS 2003, (October). https://doi.org/10.1109/HICSS.2003.1174902

Cui, Y., Zhang, X., Peng, X., \& Chu, J. (2018). How to use apology and compensation to repair competenceversus integrity-based trust violations in e-commerce. Electronic Commerce Research and Applications, 32(November), 37-48. https://doi.org/10.1016/j.elerap.2018.11.001

Dai, L., \& Wu, Y. (2015). Trust Maintenance and Trust Repair. Psychology, 06(06), $767-772$. https://doi.org/10.4236/psych.2015.66075

Eberl, P., Geiger, D., \& Aßländer, M. S. (2015). Repairing Trust in an Organization after Integrity Violations: The Ambivalence of Organizational Rule Adjustments. Organization Studies, 36(9), 1205-1235. https://doi.org/10.1177/0170840615585335

Ehrismann, M., \& Stegwee, R. A. (2015). Trust in eHealth services. (January). https://doi.org/10.13140/RG.2.1.1610.7129

Fuoli, M., \& Paradis, C. (2014). A model of trust-repair discourse. Journal of Pragmatics, 74, 52-69. https://doi.org/10.1016/j.pragma.2014.09.001 
Fuoli, M., van de Weijer, J., \& Paradis, C. (2017). Denial outperforms apology in repairing organizational trust despite strong evidence of guilt. Public Relations Review, 43(4), 645-660. https://doi.org/10.1016/j.pubrev.2017.07.007

Goyal, S., Sergi, B. S., \& Esposito, M. (2013). Social Entrepreneurship in Developing Economies Understanding the Constraining Factors and Key Focus Areas from the Literature Review. Draft, (December), 1-32.

Guinalíu, M., \& Jordán, P. (2016). Generación de confianza en el líder de equipos de trabajos virtuales. Spanish Journal of Marketing - ESIC, 20(1), 58-70. https://doi.org/10.1016/j.reimke.2016.01.003

Hadi A. A L-Abr row, Mohammad Shaker Ardakani, Alireza harooni, \& Hamidreza Moghaddam pour. (2013). The Relationship between Organizational Trust and Organizational Justice Components and Their Role in Job Involvement in Education Introduction and Problem Statement. International Journal of Management Academy, 1(1), 25-41.

Hu, L. T., \& Bentler, P. M. (1999). Cutoff criteria for fit indexes in covariance structure analysis: Conventional criteria versus new alternatives. Structural Equation Modeling, 6(1), 1-55. https://doi.org/10.1080/10705519909540118

Jenner, P., \& Oprescu, F. (2016). The Sectorial Trust of Social Enterprise: Friend or Foe? Journal of Social Entrepreneurship, 7(2), 236-261. https://doi.org/10.1080/19420676.2016.1158732

Jucks, R., \& Thon, F. M. (2017). Better to have many opinions than one from an expert? Social validation by one trustworthy source versus the masses in online health forums. Computers in Human Behavior, 70, 375-381. https://doi.org/10.1016/j.chb.2017.01.019

Kim H., P., Cooper D., C., Ferrin L., D., \& Dirks T., K. (2004). Removing the shadow of suspicion: The effects of apology versus denial for repairing competence-versus integrity-based trust violations. Journal of Applied Psychology, 89(1), 104-118. Retrieved from http://proquest.umi.com/pqdweb?did=644845411\&Fmt=7\&clientId=10306\&RQT=309\&VName=PQD

Kim, P. H., Cooper, C. D., Dirks, K. T., \& Ferrin, D. L. (2013). Repairing trust with individuals vs. groups. Organizational Behavior and Human Decision Processes, 120(1), 1-14. https://doi.org/10.1016/j.obhdp.2012.08.004

Kim, P. H., \& Harmon, D. J. (2014). Justifying one's transgressions: How rationalizations based on equity, equality, and need affect trust after its violation. Journal of Experimental Psychology: Applied, 20(4), 365379. https://doi.org/10.1037/xap0000030

Kramer, R. M., Pittinsky, T. L., \& Williams, M. (2012). Building and Rebuilding TrustWhy Perspective Taking Matters. Restoring Trust in Organizations and LeadersEnduring Challenges and Emerging Answers, 171184. https://doi.org/10.1093/acprof:oso/9780199756087.003.0009

Kunnel, A., \& Quandt, T. (2016). Trust and Communication in a Digitized World. https://doi.org/10.1007/978-3319-28059-2

Ma, F., Wylie, B. E., Luo, X., He, Z., Xu, F., \& Evans, A. D. (2018). Apologies repair children's trust: The mediating role of emotions. Journal of Experimental Child Psychology, 176, 1-12. https://doi.org/10.1016/j.jecp.2018.05.008

Manley, G. (2013). Public Access NIH Public Access. 71(2), 233-236. https://doi.org/10.1038/mp.2011.182.doi

Mayer, Roger C.; Davis, J. H. (1995). Model of Trust Theory. Academy of Management Review., 20(July), 709734.

Mayer, R. C., \& Tomlinson, E. C. (2009). The role of causal attribution dimensions in trust repair. Academy of Management Review, 34(1), 85-104.

Nickel, P. J., Franssen, M., \& Kroes, P. (2010). Can We Make Sense of the Notion of Trustworthy Technology? Knowledge, Technology \& Policy, 23(3-4), 429-444. https://doi.org/10.1007/s12130-010-9124-6

Pavlou, P. A. (2018). Consumer Acceptance of Electronic Commerce: Integrating Trust and Risk with the Technology Acceptance Model. International Journal of Electronic Commerce, 7(3), 69-103. https://doi.org/10.1080/10864415.2003.11044275

Peter H Kim, Kurt T Dirks, \& Cecily Cooper. (2009). The Repair of Trust: A Dynamic Bi-Lateral Perspective and Multi-Level Conceptualization. Academy of Management Review, 34(3), 401-422. Retrieved from http://journals.aomonline.org/InPress/main.asp?action=preview\&art_id=453\&p_id=4\&p_short=AMR

Schniter, E., Sheremeta, R. M., \& Sznycer, D. (2013). Building and rebuilding trust with promises and apologies. Journal of Economic Behavior and Organization, 94, 242-256. https://doi.org/10.1016/j.jebo.2012.09.011

Seeger, A.-M., Neben, T., \& Heinzl, A. (2017). Information failures, trust violation, and customer feedback in web-enabled transactions: the role of causal transparency as a trust repair mechanism. Proceedings of the 25th European Conference on Information Systems (ECIS), 2017, 2017-2033.

Shu, W., Chen, Y., Lin, B., \& Chen, Y. (2018). Does corporate integrity improve the quality of internal control? China Journal of Accounting Research, 11(4), 407-427. https://doi.org/10.1016/j.cjar.2018.09.002

Simon, M., \& Jiang, R. J. (2017). The role of trust in social entrepreneurship : 20(1), 46-60. 
Srivastava, S. C., Chandra, S., \& Theng, Y.-L. (2010). Evaluating the Role of Trust in Consumer Adoption of Mobile Payment Systems: An Empirical Analysis. Communications of the Association for Information Systems, 27(1), 561-588. Retrieved from https://hal.archives-ouvertes.fr/hal-00537097/

Tomlinson, E. C., \& Mayer, R. C. (2009). The role of causal attribution in trust repair. Academy of Management Review, 34(1), 85-104. https://doi.org/10.5465/amr.2009.35713291

Waddock, S., \& Steckler, E. (2016). Visionaries and Wayfinders: Deliberate and Emergent Pathways to Vision in Social Entrepreneurship. Journal of Business Ethics, 133(4), 719-734. https://doi.org/10.1007/s10551014-2451-X

Weiner, B. (2008). Attribution Theory, Achievement Motivation, and the Educational Process. Review of Educational Research, 42(2), 203-215. https://doi.org/10.3102/00346543042002203

Weitzl, W. (2016). Measuring electronic word-of-mouth effectiveness: Developing and applying the eWOM trust scale. In Measuring Electronic Word-of-Mouth Effectiveness: Developing and Applying the eWOM Trust Scale. https://doi.org/10.1007/978-3-658-15889-7

Wolfe, A. W., \& Blithe, S. J. (2015). Managing Image in a Core-Stigmatized Organization: Concealment and Revelation in Nevada's Legal Brothels. Management Communication Quarterly, 29(4), 539-563. https://doi.org/10.1177/0893318915596204

Yu, M. C., Mai, Q., Tsai, S. B., \& Dai, Y. (2018). An empirical study on the organizational trust, employeeorganization relationship and innovative behavior from the integrated perspective of social exchange and organizational sustainability. Sustainability (Switzerland), 10(3). https://doi.org/10.3390/su10030864 